\title{
Activation of human monocytes/macrophages by OHR/AVR118 promotes both pro- and anti-inflammatory phenotypes
}

\author{
Shalom Z. Hirchman \\ OHR Pharmaceutical, Inc., New York, USA \\ Email: szfebio@gmail.com \\ Received 3 December 2013; revised 3 January 2014; accepted 16 January 2014 \\ Copyright (c) 2014 Shalom Z. Hirchman. This is an open access article distributed under the Creative Commons Attribution License, \\ which permits unrestricted use, distribution, and reproduction in any medium, provided the original work is properly cited. In accor- \\ dance of the Creative Commons Attribution License all Copyrights (c) 2014 are reserved for SCIRP and the owner of the intellectual \\ property Shalom Z. Hirchman. All Copyright (C) 2014 are guarded by law and by SCIRP as a guardian.
}

\section{ABSTRACT}

The immunomodulator OHR/AVR118 has been shown to increase IL-8 and MCP-1 secretion from non-activated human monocytes and U937 pro-monocytic cells, but to decrease MCP-1 secretion from LPS-activated monocytes, suggesting its effect depends on immune cell environment and/or activation state. We therefore assessed the effect of OHR/AVR118 on cytokine secretion by human PBMCs and adherent monocytes. OHR/AVR118 increased IL-6, IL-1 $\beta$, and TNF- $\alpha$ secretion by PHA/IL-2-primed PBMCs, but did not alter IL-12 secretion. In contrast, treatment of LPS-activated monocytes decreased TNF- $\alpha$ and IL-12, increased IL-6, but did not alter IL-1 $\beta$, secretion. To further show that the effect of OHR/AVR118 depends on cellular environment, we monitored U937 differentiation towards mature macrophages in the presence of drug. OHR/AVR118 promoted a pro-inflammatory response in PMA-activated cells, as demonstrated by increased expression of the maturation markers CD86, CD32, and CD87 and by increased IL-8, MCP-1, and GM-CSF secretion. In undifferentiated U937 cells, OHR/AVR118 did not alter phagocytosis of opsonized $S$. aureus and IL-10 secretion. Whereas, after activation, OHR/AVR118 induced an anti-inflammatory phenotype, as indicated by reduced phagocytosis and increased IL-10 secretion. Overall, these findings suggest that OHR/AVR118 has a dual action on monocyte/macrophage function depending on cellular activation state, resulting in either further activation or suppression.

\section{KEYWORDS}

Peptide-Nucleic Acid; Monocytes; Chemokines; Cytokines; Inflammation

\section{INTRODUCTION}

OHR/AVR118 (previously also called Product R) is a novel immunomodulator containing a 31-amino acid peptide and a 21-residue peptide nucleic acid, in which a diadenosine is covalently attached to serine-18 via a phosphodiester bond [1]. OHR/AVR118 is chemically stable and has a favorable safety profile, both in animal toxicity studies and in human clinical trials [2]. Results of Phase 1 and early Phase 2 clinical trials indicate that OHR/ AVR118 has efficacy in treating anorexia and cachexia in severely ill patients [2-4]. As an immunomodulator, OHR/AVR118 exerts broad effects on immunocytes, especially on monocytes and macrophages. We demonstrated previously that OHR/AVR118 increases IL-8 and MCP-1 secretion by non-activated human monocytes and U937 pro-monocytic cells, but decreases MCP-1 secretion by LPS-activated monocytes [5]. These findings suggested that the effect of OHR/AVR118 on immune cells is dependent on cellular environment and/or activation state.

Monocytic dendritic and macrophage cells each play unique and essential roles in maintaining and restoring polarized immune responses [6]. Immune homeostasis involves signaling networks that control the balance between cell proliferation and cell death in response to different microenvironments [7]. We hypothesized that OHR/AVR118 affects a key step in the monocytic regulation of immune homeostasis. To characterize the effect of OHR/AVR118 during monocyte activation, we monitored the differentiation of U937 cells in the presence of drug. In addition, to understand the action of OHR/ AVR118 on primary cells, we utilized LPS-activated human blood monocytes, which are more mature than U937 cells and have been shown to respond differently 
to OHR/AVR118, most likely due to their more differentiated state. Finally, to further explore whether the effect of OHR/AVR118 on immune modulation is dependent on the cellular environment and/or activation state, we compared cytokine secretion by OHR/AVR118-treated human PBMCs with that by adherent monocytes and monocytic dendritic cells. Our results suggest that OHR/ AVR118 has both pro- and anti-inflammatory effects on monocytic cell function.

\section{MATERIALS AND METHODS}

\subsection{PBMCs}

Peripheral blood mononuclear cells (PBMCs) were isolated from Ficoll-Hypaque gradients of donor blood and cultured for 3 days in RPMI 1640 medium containing $20 \%$ fetal bovine serum (FBS), 100 units $/ \mathrm{ml}$ interleukin-2 (IL-2) and $3 \mu \mathrm{g} / \mathrm{ml}$ phytohemagglutinin (PHA), plus various concentrations of OHR/AVR118 or PBS $[5,8]$.

To generate adherent cells, PBMCs were seeded in adherence medium, RPMI 1640 supplemented with 5\% FBS, $1 \mathrm{X}$ non-essential amino acids, $0.5 \mathrm{X}$ essential amino acids, $50 \mu \mathrm{M} \beta$-mercaptoethanol, $4 \mathrm{mM}$ L-glutamine, $1 \mathrm{X}$ pen-strep, $1 \mathrm{X}$ gentamicin, $1 \mathrm{X}$ sodium pyruvate, and $0.75 \%$ glucose, and incubated for $2 \mathrm{~h}$. Non-adherent cells were removed with three washes of $\mathrm{Ca}^{+2} / \mathrm{Mg}^{+2}$-free PBS. Adherent PBMCs were activated by culture for $72 \mathrm{~h}$ in medium containing $20 \%$ FBS, $0 \%-10 \%$ OHR/AVR118 or PBS, plus, where indicated, $1 \mu \mathrm{g} / \mathrm{ml}$ E. coli 055:B5 LPS. In each experiment, all conditions were assayed in duplicate.

\subsection{U937 Activation}

Protocols for culturing U937 cells (ATCC; Manassas, VA) and for their treatment with OHR/AVR118 have been described [5]. For activation, cells, seeded at $2 \times$ $105 \mathrm{ml}$, were cultured for $48 \mathrm{~h}$ in medium containing 100 nM PMA plus 5\% OHR/AVR118 or PBS (control), with a change of medium after $24 \mathrm{~h}$, following which they were cultured for an additional $48 \mathrm{~h}$ in fresh medium containing 5\% OHR/AVR118 or PBS-control plus $1 \mu \mathrm{g} /$ $\mathrm{ml}$ E. coli 055:B5 LPS.

\subsection{Differentiation of Human Monocytic Dendritic Cells}

Adherent PBMCs were cultured for 8 days in 6-well plates with medium containing 1000 units/ml IL-4 (Pierce/Endogen, Woburn, MA) and 1000 units/ml GMCSF (Genentech, San Francisco, CA), supplemented with $5 \%$ and $10 \%$ OHR/AVR118 or PBS, replacing the medium every other day.

\subsection{ELISA of Chemokines and Cytokines}

Conditioned cell culture media were harvested, quickfrozen in liquid nitrogen, and stored until time of assay. Concentrations of human IL-8, IL-10, IL-12, IL- $1 \beta$, and TNF- $\alpha$ were measured using ELISA kits from Pierce/ Endogen, whereas concentrations of MCP-1, IL-6, and GM-CSF were measured using ELISA kits from R\&D Systems (Minneapolis, MN). Each supernatant was assayed for each cytokine concentration in triplicate. Absorbance was measured on a PowerWave 200 Microplate Scanning Spectrophotometer (Bio-Tek Instruments; Winooski, VT); concentrations were determined by extrapolation from four-parameter logistic fit standard curves generated from dilutions of standard protein supplied by the manufacturer.

\subsection{Flow Cytometry}

Phycoerythrin (PE)- or (FITC)-conjugated mouse monoclonal antibodies against human CD86 (B7.2), CD80 (B7.1), CD32 (Fc $\gamma$ RII), CD87 (uPA receptor) CD88 (C5a receptor), CD14, CD18, CD54, CD36, CD64, HLA-DR, DQ, DP (MHC-class II) and HLA-A, B, C (MHC-class I), as well as the appropriate isotype controls, were purchased from BD Biosciences/PharMingen (San Diego, CA). Immunofluorescent labeling of cells with antibody conjugates for cytometric analysis and flow cytometry was performed as described [5].

\subsection{RNA Extraction and RT-PCR}

Extractions of total RNA, reverse transcription, PCR amplification, and gel electrophoresis and scanning were performed as described [5,9].

\subsection{Phagocytosis Assay}

Following PMA-activation of U937 cells for $48 \mathrm{~h}$ in the presence of 5\% OHR/AVR118 or PBS, the cells were harvested, washed, and re-suspended in ice-cold Binding Buffer (HEPES-buffered saline containing 5\% FBS, 1\% glucose, and $1 \mathrm{mM}$ sodium pyruvate). Preformed, opsonized bacterial complexes were prepared by incubating FITC-Staphylococcus aureus (StaphA) with anti-StaphA antibodies (opsonizing reagent; Molecular Probes, Eugene, OR) in PBS for 1 hour at $37^{\circ} \mathrm{C}$, followed by cooling on ice. For non-specific binding, cells were incubated with $20 \mathrm{mg} / \mathrm{ml}$ of yeast mannan (Molecular Probes) for $10 \mathrm{~min}$ at $37^{\circ} \mathrm{C}$. PMA-activated U937 were incubated with opsonized or non-opsonized FITC- or BoDipyFITC-labeled StaphA (Molecular Probes), at a 30:1 bacteria to cell ratio, in ice-cold Binding Buffer for $1 \mathrm{~h}$ on ice. Uptake was initiated by adding pre-warmed Binding Buffer and incubating cells at $37^{\circ} \mathrm{C}$ for $10,30,60$ and $120 \mathrm{~min}$. The cells were cooled by adding an excess of 
ice-cold PBS containing $1 \%$ FBS and $0.02 \%$ sodium azide (PBS Wash) and transferred to ice. All further manipulations were performed on ice with cold buffers. Cells were washed thrice with PBS Wash and once with PBS, resuspended in PBS, and analyzed by flow cytometry. In some experiments, the fluorescence from cell surface-bound bacteria from replicate samples was quenched with $4 \%$ trypan blue in citrate buffer, $150 \mathrm{mM} \mathrm{NaCl}$, $\mathrm{pH}$ 5.1. In other experiments, the amount of surface bound bacteria was measured using cells incubated at $0^{\circ} \mathrm{C}$ throughout. Cells were also labelled with propidium iodide to exclude nonviable cells. Flow cytometry analysis of the cell-associated fluorescence was used to determine the percentage of phagocytic cells (i.e. those with positive fluorescence exceeding those of the cold bind or trypan blue controls) and extent of uptake (fluorescence intensity). To confirm the extent of activation, the secretion of IL-8 and MCP-1 and the surface expression of CD86 and CD32 were determined in all phagocytosis experiments.

\section{RESULTS}

\subsection{OHR/AVR118 Stimulates Chemokine/Cytokine Secretion by Activated PBMCs}

Treatment of activated PBMCs with an early preparation of OHR/AVR118, was found to increase expression of IL-6 and IL- $1 \beta$ mRNA [8]. To confirm and extend these findings, we measured the effect of OHR/AVR118 on secretion of these cytokines under similar conditions. PBMCs were cultured with varying concentrations of OHR/AVR118 for 24 and $48 \mathrm{~h}$ in the presence of PHA and IL-2. Consistent with previous findings, OHR/ AVR118 stimulated the secretion of both IL- 6 and IL- $1 \beta$ in a dose- and time-dependent manner (Figure 1). Since cells of the monocyte/macrophage lineage are major sources of IL-6 and IL- $1 \beta[10,11]$ the effect of OHR/ AVR118 on the secretion of chemokines and cytokines was tested on PBMC-derived adherent monocytes.

\subsection{OHR/AVR118 Alters the Secretion of Chemokines/Cytokines by Activated Monocytes}

The endotoxin LPS stimulates monocytes to produce several cytokines and chemokines, including IL-6, IL-1 $\beta$, IL-12, TNF- $\alpha$ and GM-CSF [12-14]. To test the effects of OHR/AVR118 on LPS-induced cytokine secretion, PBMC-derived monocytes were cultured in the presence of LPS and varying concentrations of OHR/AVR118 for $72 \mathrm{~h}$. As with total PBMCs, AVR118 stimulated LPSactivated monocytes to secrete increased amounts of IL-6 (Figure 2(A)). In addition, OHR/AVR118 induced a dose-dependent increase in the secretion of GM-CSF
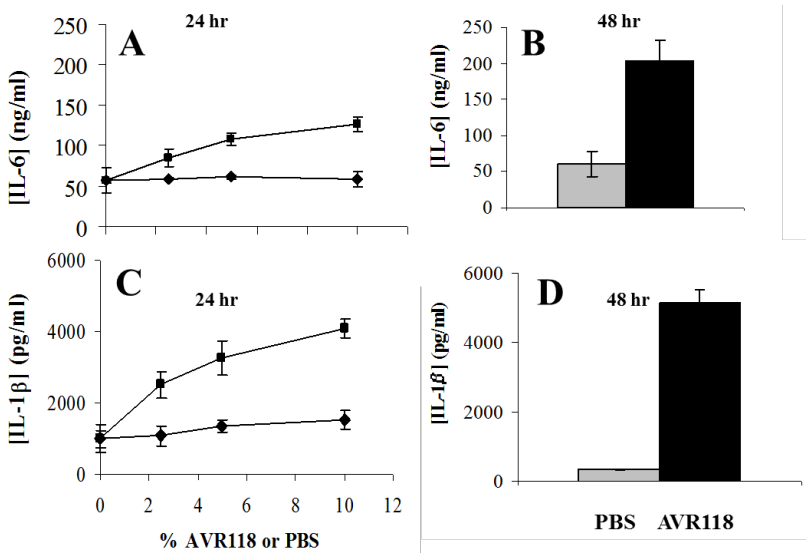

Figure 1. OHR/AVR118-enhanced IL-6 and IL-1 $\beta$ secretion by PHA/IL-2-activated PBMCs. $4 \times 10^{6}$ PBMCs were added to each well of a 6-well tissue culture plate and incubated for 2 days with IL-2 (5\%) and PHA (3 $\mu \mathrm{g} / \mathrm{ml})$. The cells were fed fresh media containing $0 \%-10 \%$ OHR/AVR118 or PBS for 3 days, and secreted cytokines were measured by ELISA. (A, C) Secretion of IL-6 (A) and IL-1 $\beta$ (C) in 24 h relative to concentration of OHR/AVR118 (squares) or PBS (circles). (B, D) Secretion of IL-6 (B) and IL-1 $\beta$ (D) in $48 \mathrm{~h}$ in response to $10 \%$ OHR/AVR118 (black) or PBS (grey). Results shown are representative of at least 2 independent experiments.
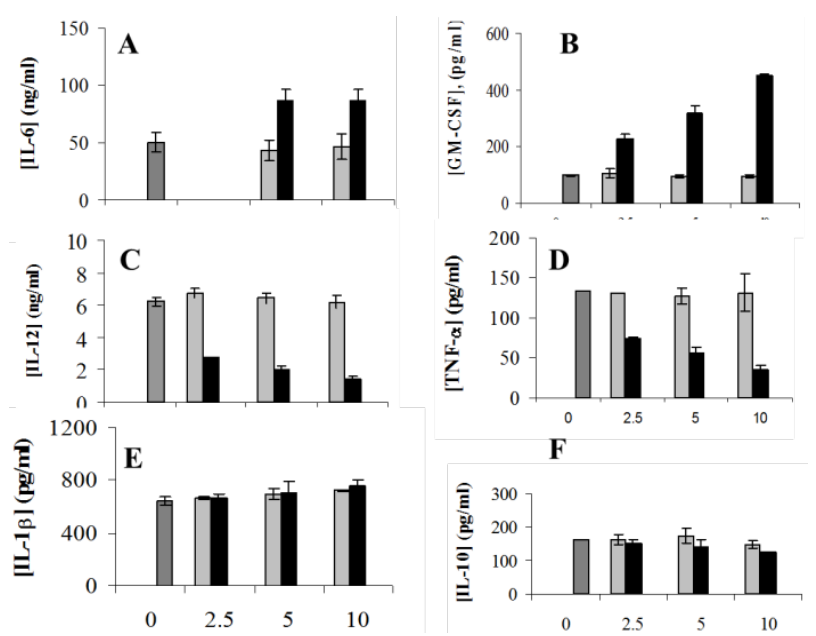

Figure 2. OHR/AVR118-altered cytokine secretion by LPSactivated human monocytes. $4 \times 10^{6}$ PBMCs were added to each well of a tissue culture dish and incubated for $2 \mathrm{~h}$. The adherent cells were washed and cultured for 3 days in media containing $0 \%$ - 10\% OHR/AVR118 (black) or PBS (light gray), and secreted IL-6 (A), GM-CSF (B), IL-12 (C), TNF- $\alpha$ (D), IL-1 $\beta$ (E), and IL-10 (F) were measured by ELISA; untreated cells are shown in dark gray. Results shown are representative of at least 2 independent experiments.

(Figure 2(B)), similar to findings in total PBMCs (data not shown). Interestingly, increasing concentrations of OHR/ AVR118 suppressed the LPS-induced secretion of IL-12 and TNF- $\alpha$ by adherent monocytes (Figures 2(C) and (D)). In contrast to its stimulation of IL- $1 \beta$ secretion by PBMCs, OHR/AVR118 did not alter IL- $1 \beta$ secretion by 
LPS-activated monocytes (Figure 2(E)) and had no effect on the secretion of IL-10 (Figure 2(F)).

Primary monocytic cells can be driven by GM-CSF and IL-4 to differentiate into dendritic cells in vitro. We tested the effect of OHR/AVR118 on monocytes cultured for 4 - 8 days with GM-CSF and IL-4. Control cells showed a time-dependent increase in IL-12 secretion, which reached a maximum on day 6 , but very little secretion of IL-6. When cultured in the presence of OHR/ AVR118 for 8 days, however, monocytic dendritic cells showed a 3.7-fold increase in IL-6 secretion, but a 2.9fold decrease in IL-12 secretion, compared with control cells (Figure 3).

\subsection{OHR/AVR118 Modulates Surface Expression and Cytokine/Chemokine Secretion by Activated U937 Cells}

We previously showed the dual response of resting versus activated primary monocytes to OHR/AVR118 [5]. In addition, animal model studies suggest that OHR/ AVR118 may have alternative effects depending upon the initial state of the immune response (Cahalon L, Cohen I, personal communication). To determine further whether OHR/AVR118 has both pro- and anti-inflammatory properties, we treated U937 cells with OHR/ AVR118 or PBS during PMA activation for 2 - 3 days. We observed increased per cell expression of various markers characteristic of differentiating macrophages, including the costimulatory marker CD86 (B7.2) and the functional receptors CD87 (uPA receptor) and CD32 ( $F c \gamma$ RII), as well as increases in the percentage of cells positive for CD86 and CD87 (Figure 4). AVR118 decreased the per cell expression of the MHC-class I receptors HLA-A, -B and -C, while not altering the percentage of cells positive for CD32 and MHC-class I (Figure 4). Modest increases in the per cell expression of

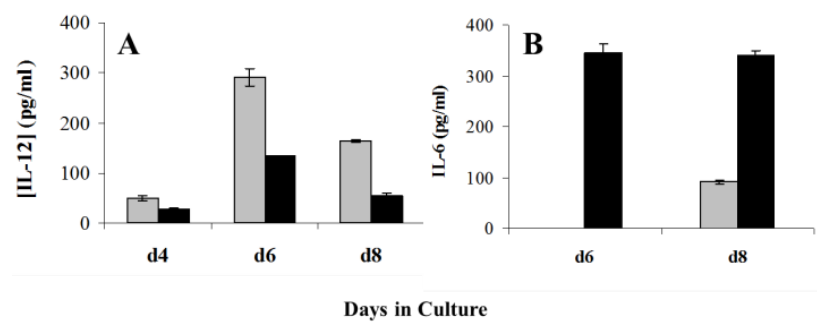

Figure 3. OHR/AVR118-altered secretion of IL-12 and IL-6 by differentiating monocytic dendritic cells. Adherent monocytes were differentiated to monocytic dendritic cells by culture for 4 , 6 or 8 days (d4, d6 and d8) with IL-4 and GM-CSF, plus 5\% PBS or OHR/AVR118; the cells were re-fed every 2 days. Conditioned tissue culture media were harvested on d6 and d8, and secreted IL-12 (A) and IL-6 (B) were measured by ELISA (untreated, dark gray; PBS, light gray; OHR/AVR118, black). Results shown are representative of at least 2 independent experiments.

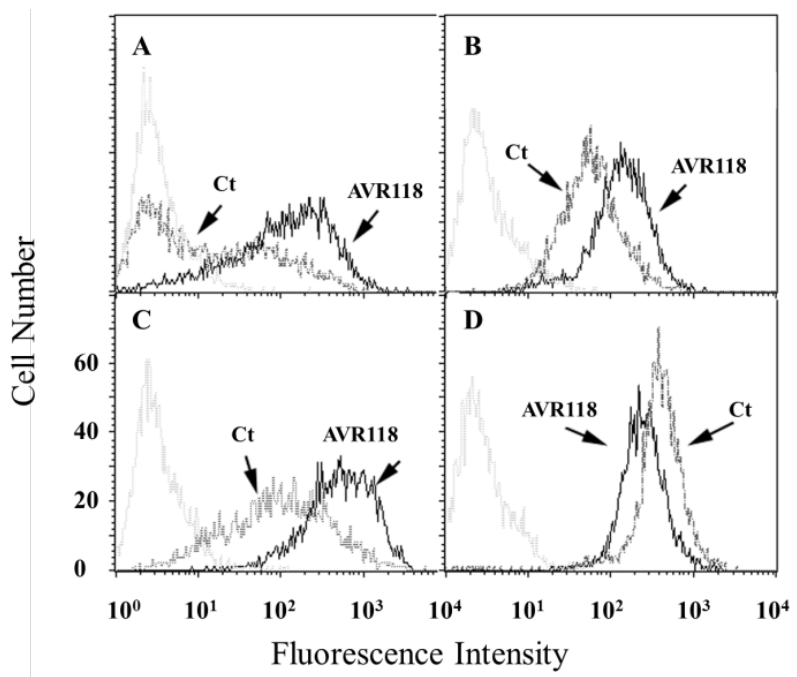

Figure 4. OHR/AVR118-altered surface expression of maturation markers on PMA-activated U937 cells. U937 cells were cultured with 100 nM PMA plus 5\% OHR/AVR118 or PBS for $48 \mathrm{~h}$, harvested and labeled with fluorescently conjugated antibodies to CD86 (A; B7.2), CD32 (B; Fcy-Receptor II), CD87 (C; uPA receptor), and HLA-A, -B, -C (D; MHC-class I), prior to flow cytometry. Isotype controls were used as negative controls. Histograms represent fluorescence intensity as a function of cell number. Results shown are representative of at least 10 independent experiments.

CD14 and CD18 were also observed, as well as a large increase in the surface expression of CD88 (C5a receptor) (data not shown). RT-PCR showed that OHR/AVR118 enhanced the expression of CD86, CD32, CD54, CD87, CD18, CD88, and CD80 mRNAs, but only slightly increased the expression of CD14 mRNA, in PMA-activated U937 cells (data not shown).

U937 cells further activated with LPS for $48 \mathrm{~h}$ in the presence of OHR/AVR118 showed increased overall levels of CD32, CD86, CD87, CD88, and CD14 compared with control activated cells. In contrast, OHR/ AVR118 had no effect on the surface expression of CD54, the MHC-class II receptors HLA-DR, -DQ, and -DP, and CD80, and decreased the surface expression of HLA-A, -B, -C (MHC-class I), CD36 and CD64 (data not shown).

Similar to our results with primary monocytes, we found that treatment for 24 - $48 \mathrm{~h}$ with OHR/AVR118 enhanced the PMA-induced secretion of IL-8, MCP-1, GM-CSF, and IL- $1 \beta$ and the expression of each mRNA (data not shown). In addition, OHR/AVR118 enhanced the secretion of the anti-inflammatory cytokine IL-10, after both PMA- and LPS-activation (Figure 5). OHR/ AVR118 had a differential effect on IL-6 secretion, stimulating its secretion by PMA-activated U937 cells, but markedly inhibiting its secretion by cells further stimulated with LPS (Figure 6); this differential response to OHR/AVR118 was confirmed by RT-PCR (data not 

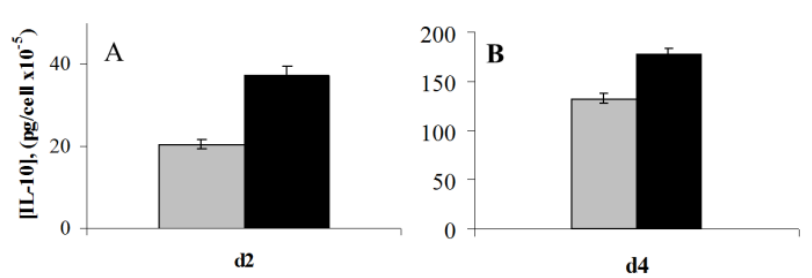

Figure 5. OHR/AVR118-increased IL-10 secretion by PMAand LPS-activated U937 Cells. (A) U937 cells were cultured for 2 days in medium containing $1 \mathrm{nM}$ PMA and 5\% OHR/ AVR118 (black) or PBS (gray), and (B) for an additional 2 days in medium containing $1 \mu \mathrm{g} / \mathrm{ml}$ E. coli 055:B5 LPS and 5\% OHR/AVR118 or PBS, and the concentration of secreted IL-10 was measured by ELISA. Results shown are representative of at least 4 independent experiments.
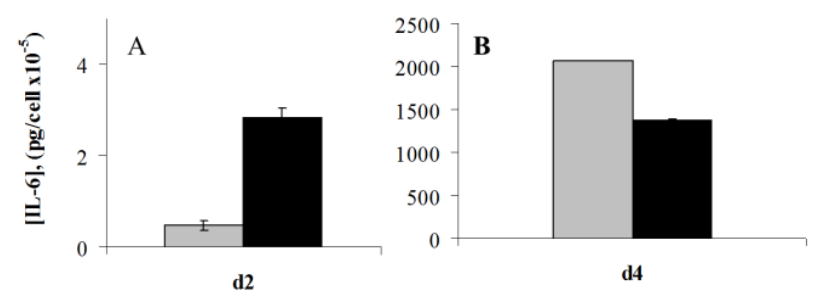

Figure 6. Dual effect of OHR/AVR118 on IL-6 secretion by activated U937 cells. U937 cells were cultured with (A) PMA and (B) LPS, in the presence of 5\% OHR/AVR118 (black) or PBS (gray), as described in the Legend to Figure 5, and the concentrations of secreted IL-6 were measured by ELISA. Results shown are representative of at least 4 independent experiments.

shown). It should be noted that these cells did not express IL-12 or CD40 mRNA or protein (data not shown).

\subsection{OHR/AVR118 Inhibits the Phagocytic Capacity of PMA-Activated U937 Cells}

PMA activation of U937 cells increases their phagocytic capacity, a characteristic of differentiated macrophages. To determine the effect of OHR/AVR118 on this activity, we monitored cellular uptake of FITC-labeled StaphA following culture for $48 \mathrm{~h}$ with PMA plus 5\% OHR/ AVR118 or PBS. Surprisingly, OHR/AVR118 inhibited phagocytosis of FITC-labeled bacteria by PMA-activated U937 cells, indicating that OHR/AVR118 inhibits the pro-inflammatory responses of highly activated (mature) monocytic cells (Figure 7). OHR/AVR118 reduced the uptake the uptake of opsonized StaphA particles, as well as the percentage cells exhibiting uptake of opsonized and non-opsonized StaphA complexes.

\section{DISCUSSION}

Activated macrophages are important mediators of inflammatory responses to infectious agents [15]. Chronic activation of inflammatory macrophages, however, can lead to tissue damage in autoimmune diseases, such as
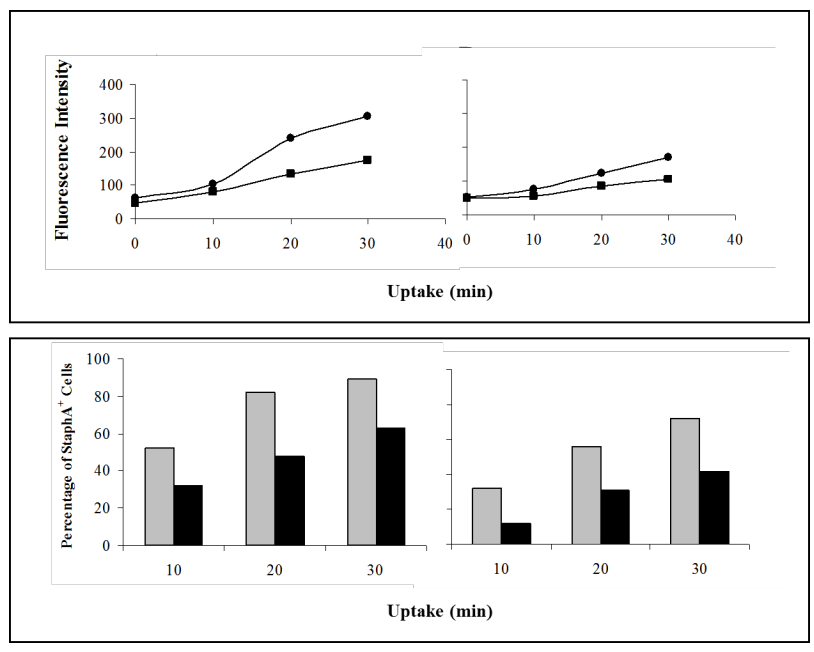

Figure 7. Effect of OHR/AVR118 on PMA-activated U937 phagocytosis of FITC-StaphA. PMA-U937 cells generated in the presence of 5\% OHR/AVR118 or PBS were incubated with FITC-conjugated Staphylococcus aureus (StaphA) at $37^{\circ} \mathrm{C}$ for 0 , 10, 20, and $30 \mathrm{~min}$, and uptake of opsonized (A, C) and nonopsonized (B, D) particles was measured by flow cytometric. (A, B) Total cell-associated fluorescence intensity relative to incubation time at $37^{\circ} \mathrm{C}$ (squares, OHR/AVR118; circles, PBS). (C, D) Percent FITC-StaphA-positive cells relative to incubation time at $37^{\circ} \mathrm{C}$ (black bars, OHR/AVR118; gray bars, PBS). Results shown are representative of at least 6 independent experiments.

rheumatoid arthritis and systemic lupus erythematosus [16]. Evidence establishing a link between the innate and adaptive immune responses suggests that macrophages and dendritic cells are major mediators of immune system balance, as shown by the identification of immunosuppressive macrophages in the "alternatively-activated macrophage” cell population $[7,17,18]$. Inhibitory receptors are one class of proteins that regulate negative feedback signals to suppress chronic inflammatory responses [19]. Chemokines and cytokines can stimulate or inhibit inflammation, with the same molecule showing stimulatory or inhibitory activity under different conditions [20]. Our previous findings indicated that OHR/AVR118 can also stimulate or inhibit monocyte activity under different conditions [5]. We therefore sought to identify the key molecular regulators in the switch-type monocyte/ macrophage response to OHR/AVR118. The results presented here provide further evidence that OHR/AVR118 is a novel immunomodulatory drug, which can promote both pro- and anti-inflammatory phenotypes of monocytes in culture. Our findings thus support a role for OHR/AVR118 as a homeostatic immune modulator of monocytic cells.

Among the most important pro-inflammatory mediators are the chemokines IL- 8 and MCP-1, which are produced primarily by cells of the monocyte/macrophage lineage and chemoattract immune system cells to the si- 
tes of immune responses, with IL-8 mainly chemoattracting neutrophils and MCP-1 monocytes/macrophages [21]. We previously showed that OHR/AVR118 enhances MCP-1 secretion by unstimulated monocytes but inhibits MCP-1 secretion by LPS-stimulated monocytes, suggesting that the activity of OHR/AVR118 on monocytes depends on their maturation stage [5]. The results presented here, showing the effects of OHR/AVR118 on the secretion of other cytokines by LPS-stimulated monocytes, provide further evidence for the multiple, maturation stage dependent effects of OHR/AVR118 on LPSactivated adherent monocytes.

In testing the effects of OHR/AVR118 during the differentiation of pro-monocytic U937 cells towards mature macrophages, we found that OHR/AVR118 enhanced the PMA-associated expression of many maturation markers characteristic of the macrophage phenotype and increased the secretion of pro-inflammatory cytokines. In undifferentiated U937 cells, OHR/AVR118 had no effect on StaphA phagocytosis or IL-10 secretion, but, following activation and maturation, OHR/AVR118 inhibited phagocytosis of opsonized and non-opsonized StaphA and increased IL-10 secretion, providing further evidence that OHR/AVR118 inhibits the pro-inflammatory responses of mature monocytic cells. The dual immunomodulatory activity of OHR/AVR118 is also supported by our findings on the effects of OHR/AVR118 on the secretion of IL-6, a key modulator of immune system balance. We found that OHR/AVR118 increased IL-6 secretion by PMA-activated U937 cells but markedly reduced its secretion by cells additionally stimulated with LPS.

Phagocytosis is important in the regulation of immune responses to pathogens and to self-antigens [22]. FcR and TLR signaling are among the pathways that regulate phagocytosis in mononuclear macrophages and are essential in both the innate and cellular immune responses [23]. We found that OHR/AVR118 increased the cell surface expression of $\mathrm{F}_{\mathrm{C}} \gamma \mathrm{RII}$ (CD32), a pro-inflammatory receptor that mediates phagocytosis, on PMA-primed U937 cells. Surprisingly, these same cells exhibited reduced phagocytic capacity, both in the percentage of phagocytic-competent cells as well as per-cell uptake of bacterial particles. This seemingly contradictory result may be due to the overall balance in expression of other types of $F_{C}$ receptors. Indeed, OHR/AVR118 decreased the expression of $\mathrm{F}_{\mathrm{C}} \gamma \mathrm{RIII}$ (CD64) by PMA-activated U937 cells. In addition, the balance in CD32 isoform expression may change in response to drug treatment. Since one isoform, ( $\left.\mathrm{F}_{\mathrm{C}} \gamma \mathrm{RII}-\mathrm{A}\right)$ stimulates, whereas the other $\left(\mathrm{F}_{\mathrm{C}} \gamma \mathrm{RII}-\mathrm{B}\right)$, inhibits phagocytosis and $\mathrm{Fc}_{\mathrm{c}}$ receptor signaling in macrophages, the balanced expression of these isoforms is essential in balancing immune responses dependent upon $\mathrm{F}_{\mathrm{C}} \gamma \mathrm{RII}$ signaling and phagocytosis, and imbalances have been implicated in autoimmune dysfunction [24-26]. Interestingly, studies using transgenic null mutants of $\mathrm{F}_{\mathrm{C}} \gamma \mathrm{RII-B}$ have demonstrated that this receptor is involved in promoting strong cell-mediated responses and immunological memory [27]. In preliminary experiments, we found that OHR/AVR118 increased $\mathrm{F}_{\mathrm{C}} \gamma \mathrm{RII-B}$ mRNA expression, but had no effect on $\mathrm{F}_{\mathrm{C}} \gamma \mathrm{RII}-\mathrm{A}$ mRNA expression, and western blotting experiments showed that AVR118 increased total CD32 and $\mathrm{F}_{\mathrm{C}} \gamma$ RII-A protein expression (data not shown).

The OHR/AVR118-induced reduction in phagocytic activity of PMA-stimulated U937 cells included the uptake of non-opsonized particles; suggesting that OHR/ AVR118 affects other receptors involved in phagocytosis under non-opsonizing conditions. Mannose and CD163 scavenger receptors were not expressed by these cells (data not shown), but we observed OHR/AVR118-associated increased surface expression of CD88 (C5a receptor) and decreased expression of CD36 scavenger receptor. Inhibition of chronic phagocytic activity would be an advantage in controlling an over-stimulated immune response and restoring immune homeostasis. Our finding, that OHR/AVR118 inhibited IL-12 secretion by activated monocytes, is consonant with its inhibition of the development of experimental allergic encephalitis and adjuvant arthritis in rats (L. Cahalon, I. Cohen, unpublished results). Increased production of IL-12 has been found to be important in mediating inflammatory responses in these animal models $[28,29]$.

OHR/AVR118 showed an unexpected dichotomy on the secretion of pro-inflammatory IL-12 and GM-CSF by LPS-activated monocytes. Secretion of these cytokines is usually concordant [30]. The OHR/AVR118-induced inhibition of IL-12 secretion may be fundamental to its dual immunomodulatory properties, in that increased production of IL-12 may commit the immune system to an inflammatory response not easily reversed or modulated. Inhibition of IL-12 secretion may allow OHR/ AVR118 to cycle pro-inflammatory responses between activated or suppressed states. Interestingly, OHR/AVR118 reduced IL-12 secretion by both LPS-activated and IL-4/GM-CSF stimulated monocytes.

The differential effects of an immunomodulator such as OHR/AVR118 on the secretion of chemokines/cytokines should not be surprising in light of the broad effects of immunomodulators on immune function. Further work is needed to identify the activation phenotype observed with OHR/AVR118, as well as to understand the mechanisms that regulate the maturation pathway of activated macrophages. The dual function of OHR/AVR118 may serve to restore immune homeostasis. OHR/ AVR118 may therefore prove valuable in treating illnesses that require the stimulation of pro-inflammatory responses, such as cancers, as well as illnesses that re- 
quire the inhibition of aberrant inflammatory responses, such as autoimmune diseases.

\section{ACKNOWLEDGEMENTS}

The author thanks Dr. Richard Alexander, Dr. Maribel De Diego and Dr. Deborah Lazzarino for their assistance.

\section{REFERENCES}

[1] Friedland, B., Hirschman, S.Z. and Taraporewala, I.B. (2005) Preparation of a therapeutic composition. US Patent No. 6,921,542.

[2] Levett, P.N., Hirschman, S.Z., Roach, T.C., Broome, H., Alexander, R.J. and Fraser, H.S. (2002) Randomized, placebo-controlled trial of product $\mathrm{R}$, a peptide-nucleic acid immunomodulator, in the treatment of adults infected with HIV. HIV Clinical Trials, 3, 272-278. http://dx.doi.org/10.1310/N34A-653T-ABF5-8Q1R

[3] Olimpio, J.T., Hirschman, S.Z., Shtemer, Z. and Didiego, M. (2004) Anti-cachectic effects of a novel peptide-nucleic acid: preliminary results of a phase I/II clinical trial. Journal of Clinical Oncology, 22, 8087.

[4] Chasen, M., Hirschman, S.Z. and Bhargava, R. (2012) Phase II study of the novel peptide nucleic acid OHR118 in the management of cancer-related anorexia/cachexia. Journal of the American Medical Directors Association, 12, 62-67. http://dx.doi.org/10.1016/j.jamda.2010.02.012

[5] Lazzarino, D.A., de Diego, M., Hirschman, S.Z., Zhang, K.Y., Shaikh, S., Musi, E., Liaw, L., et al. (2001) IL-8 and MCP-1 secretion is enhanced by the peptide-nucleic acid immunomodulator, Product R, in U937 cells and primary human monocytes. Cytokine, 14, 234-239. http://dx.doi.org/10.1006/cyto.2001.0867

[6] Mantovani, A., Schioppa, T., Biswas, S.K., Marchesi, F., Allavena, P. and Sica, A. (2003) Tumor-associated macrophages and dendritic cells as prototypic Type II polarized myeloid populations. Tumori, 89, 459-468.

[7] Nagy, Z.S., Ross, J., Cheng, H., Stepkowski, S.M. and Kirken, R.A. (2004) Regulation of lymphoid cell apoptosis by Jaks and Stats. Critical Reviews in Immunology, 24, 87-110.

http://dx.doi.org/10.1615/CritRevImmunol.v24.i2.10

[8] Hirschman, S.Z. and Chen, C.W. (1996) Peptide nucleic acids stimulate gamma interferon and inhibit the replication of the human immunodeficiency virus. Journal of Investigative Medicine, 44, 347-351.

[9] Lazzarino, D.A., De Diego, M., Musi, E., Hirschman, S.Z. and Alexander, R.J. (2000) CCR5 and CXCR4 expression by H9 T-cells is downregulated by a peptide-nucleic acid immunomodulator. Immunology Letters, 74, 189-195. http://dx.doi.org/10.1016/S0165-2478(00)00258-3

[10] Navarro, S., Debili, N., Bernaudin, J.F., Vainchenker, W. and Doly, J. (1989) Regulation of the expression of IL-6 in human monocytes. The Journal of Immunology, 142, 4339-4345.

[11] Elias, J.A., Schreiber, A.D., Gustilo, K., Chien, P., Rossman, M.D., Lammie, P.J., et al. (1985) Differential in- terleukin 1 elaboration by unfractionated and density fractionated human alveolar macrophages and blood monocytes: Relationship to cell maturity. The Journal of Immunology, 135, 3198-3204.

[12] Sallerfors, B. and Olofsson, T. (1992) Granulocyte-macrophage colony-stimulating factor (GM-CSF) and granulocyte colony-stimulating factor (G-CSF) secretion by adherent monocytes measured by quantitative immunoassays. European Journal of Haematology, 49, 199-207. http://dx.doi.org/10.1111/j.1600-0609.1992.tb00047.x

[13] Agarwal, S., Piesco, N.P., Johns, L.P. and Riccelli, A.E. (1995) Differential expression of IL-1 beta, TNF-alpha, IL-6, and IL-8 in human monocytes in response to lipopolysaccharides from different microbes. Journal of Dental Research, 74, 1057-1065. http://dx.doi.org/10.1177/00220345950740040501

[14] Hayes, M.P., Wang, J. and Norcross, M.A. (1995) Regulation of interleukin-12 expression in human monocytes: Selective priming by interferon gamma of lipopolysaccharide-inducible p35 and p40 genes. Blood, 86, 646-650.

[15] Morrissette, N., Gold, E. and Aderem, A. (1999) The macrophage-A cell for all seasons. Trends in Cell Biology, 9, 199-201. http://dx.doi.org/10.1016/S0962-8924(99)01540-8

[16] Duffield, J.S. (2003) The inflammatory macrophage: A story of Jekyll and Hyde. Clinical Science, 104, 27-38. http://dx.doi.org/10.1042/CS20020240

[17] Goerdt, S., Politz, O., Schledzewski, K., Birk, R., Gratchev, A., Guillot, P., et al. (1999) Alternative versus classical activation of macrophages. Pathobiology, 67, 222226. http://dx.doi.org/10.1159/000028096

[18] Mantovani, A., Sozzani, S., Locati, M., Allavena, P. and Sica, A. (2002) Macrophage polarization: Tumor-associated macrophages as a paradigm for polarized M2 mononuclear phagocytes. Trends in Immunology, 23, 549555. http://dx.doi.org/10.1016/S1471-4906(02)02302-5

[19] Leibson, P.J. (2004) The regulation of lymphocyte activation by inhibitory receptors. Current Opinion in Immunology, 16, 328-336. http://dx.doi.org/10.1016/j.coi.2004.03.006

[20] Kildsgaard, J., Hollmann, T.J., Matthews, K.W., Bian, K., Murad, F. and Wetsel, R.A. (2000) Cutting edge: Targeted disruption of the C3a receptor gene demonstrates a novel protective anti-inflammatory role for C3a in endotoxin-shock. The Journal of Immunology, 165, 54065409.

[21] Krakauer, T., Vilcek, F. and Oppenheim, J.J. (1999) Proinflammatory chemokines. TNF and IL-1 families, chemokines, TGF-beta, and others. In: Paul, W.E., Ed., Fundamental Immunology, 4th Edition, Lippincott-Raven Publishers, Philadelphia, 775-811.

[22] Greenberg, S. and Grinstein, S. (2002) Phagocytosis and innate immunity. Current Opinion in Immunology, 14, 136-145. http://dx.doi.org/10.1016/S0952-7915(01)00309-0

[23] Taylor, P.R., Martinez-Pomares, L., Stacey, M., Lin, H.H., Brown, G.D. and Gordon, S. (2005) Macrophage receptors and immune recognition. Annual Review of Im- 
munology, 23, 901-944.

http://dx.doi.org/10.1146/annurev.immunol.23.021704.11 $\underline{5816}$

[24] Hunter, S., Indik, Z.K., Kim, M.K., Cauley, M.D., Park, J.G. and Schreiber, A.D. (1998) Inhibition of Fcgamma receptor-mediated phagocytosis by a nonphagocytic Fcgamma receptor. Blood, 91, 1762-1768.

[25] Clynes, R., Maizes, J.S., Guinarmard, R., Ono, M., Takai, T. and Ravetch, J.V. (1999) Modulation of immune complex-induced inflammation in vivo by the coordinate expression of activation and inhibitory Fc receptors. The Journal of Experimental Medicine, 189, 179-185. http://dx.doi.org/10.1084/jem.189.1.179

[26] Wijngaarden, S., van de Winkel, J.G., Jacobs, K.M., Nijlsma, J.W., Lafeber, F.P. and van Roon, J.A. (2004) A shift in the balance of inhibitory and activating Fcgamma receptors on monocytes toward the inhibitory Fcgamma receptor IIb is associated with prevention of monocyte activation in rheumatoid arthritis. Arthritis \& Rheuma- tology, 50, 3878-3887.

http://dx.doi.org/10.1002/art.20672

[27] Fukuyama, H., Nimmerjahn, F. and Ravetch, J.V. (2005) The inhibitory Fcgamma receptor modulates autoimmunity by limiting the accumulation of immunoglobulin $\mathrm{G}^{+}$ anti-DNA plasma cells. Nature Immunology, 6, 99-106. http://dx.doi.org/10.1038/ni1151

[28] Bright, J.J., Musuro, B.F., Du, C. and Sriram, S. (1998) Expression of IL-12 in CNS and lymphoid organs of mice with experimental allergic encephalitis. Journal of Neuroimmunology, 82, 22-30. http://dx.doi.org/10.1016/S0165-5728(97)00184-7

[29] Ortmann, R.A. and Shevach, E.M. (2001) Susceptibility to collagen-induced arthritis: Cytokine-mediated regulation. Clinical Immunology, 98, 109-118. http://dx.doi.org/10.1006/clim.2000.4961

[30] Cavaillon, J.M. (1994) Cytokines and macrophages. Biomedicine \& Pharmacotherapy, 48, 445-453. http://dx.doi.org/10.1016/0753-3322(94)90005-1 